\title{
SIAPP: uma proposta de análise sobre política pública para a educação
}

\author{
Elissandro dos Santos Santana \\ Professor da Faculdade Nossa Senhora de Lourdes e do Evolução Centro Educacional \\ Avaliador científico das Revistas de Direito da Cidade e da Quaestio Iuris da UERJ \\ Revisor e tradutor da Revista Latinoamérica \\ Colunista e tradutor do Portal Desacato \\ 凶 elissandross@gmail.com \\ Fabiano Ferreira Machado \\ Geógrafo, Professor do Evolução Centro Educacional e do Complexo Integrado de Educação de Porto Seguro - CIEPS \\ Mestrando do Programa de Pós-graduação em Estado e Sociedade da Universidade Federal do Sul da Bahia \\ 凶fgeo84@yahoo.com.br
}

Recebido em 4 de abril de 2019

Aceito em 18 de abril de 2019

\section{Resumo:}

Este texto ensaístico configura-se como uma análise do modelo de implementação do Sistema de Apoio à Prática Pedagógica - SIAPP - adotado pelo governo do Estado da Bahia, com foco em um Estudo de Caso e Observação Participante com os professores que atuam no Complexo Integrado de Educação de Porto Seguro - CIEPS. Diante dos estudos dos diversos modelos de implantação de Políticas Públicas (PP) analisados no componente - Políticas Públicas Comparadas - no Programa de Pós-Graduação em Estado e Sociedade (PPGES) pela Universidade Federal do Sul da Bahia (UFSB) e de parceria com o outro autor deste ensaio, diversos questionamentos emergiram - motivação para a realização da proposta em baila. Para a consecução da pesquisa, foi feita uma proposta para viabilizar a política pública com base na literatura sobre o tema, cabendo destacar que os modelos privilegiados neste trabalho foram o top-down e o bottom-up à luz dos burocratas de nível de rua. Por fim, propôs-se uma análise da problemática a partir da mirada ao revés.

Palavras-chave: Educação, Políticas públicas, Top-down, Bottom-up.

\section{SIAPP: una propuesta de análisis sobre política pública para la educación}

\section{Resumen:}

Este texto ensayado se configura como un análisis del modelo de implementación del Sistema de Apoyo a la Práctica Pedagógica - SIAPP - adoptado por el gobierno del Estado de Bahía, con foco en un Estudio de Caso y Observación Participante con los profesores que actúan en el Complejo Integrado de Educación de Porto Seguro - CIEPS. En el marco de los estudios de los diversos modelos de implantación de Políticas Públicas (PP) analizados en el componente - Políticas Públicas Comparadas - en el Programa de Postgrado en Estado y Sociedad (PPGES) - por la Universidad Federal del Sur de Bahía (UFSB) y de asociación con el otro autor de este ensayo, diversos cuestionamientos surgieron - motivación para la realización de la propuesta en baila. Para la consecución de la investigación, se hizo una propuesta para viabilizar la política pública con base en la literatura sobre el tema, cabiendo destacar que los modelos privilegiados en este trabajo fueron el top-down y el bottom-up a la luz de los burócratas de nivel de calle. Por último, se propuso un análisis de la problemática a partir de la mirada al revés.

Palabras clave: Educación, Políticas públicas, Top-down, Bottom-up. 


\title{
SIAPP: a proposal for analysis on public policy for education
}

\begin{abstract}
:
This essay text is an analysis of the implementation model of the Pedagogical Practice Support System SIAPP - adopted by the State of Bahia, with a focus on a Case Study and Participant Observation with the teachers who work in the Complex Education Institute of Porto Seguro - CIEPS. In view of the studies of the different models of Public Policy (PP) implementation analyzed in the component - Public Policies Compared - in the Postgraduate Program in State and Society (PPGES) by the Federal University of Southern Bahia (UFSB) and in partnership with another author of this essay, several questions emerged motivation for the realization of the proposal in dance. In order to achieve the research, a proposal was made to make public policy feasible based on the literature on the subject, and it should be noted that the privileged models in this work were the top-down and the bottom-up in the light of street-level bureaucrats. Finally, it was proposed an analysis of the problematic from the inside out.
\end{abstract}

Keywords: Education, Public politics, Top-down, Bottom-up.

\section{CONTEXTUALIZAÇÃO NECESSÁRIA ACERCA DO OBJETO DE ESTUDO}

A proposta desta ensaística de pesquisa é realizar uma análise do modelo de implementação do SIAPP adotado pelo Governo do Estado da Bahia com foco em um Estudo de Caso e em Observação Participante com os professores que atuam no Complexo Integrado de Educação de Porto Seguro - CIEPS $^{1}$. Além disso, verificar as respectivas consequências desta implementação. Ao final, será feita uma proposta alternativa para viabilizar a política pública à luz da literatura sobre o tema.

O "Sistema de Apoio à Prática Pedagógica (SIAPP). Guia Prático: Cadastro de Plano de Curso. Versão 1.0 - 2017" (BARRETO, 2018) é um recurso interativo desenvolvido pela Secretaria da Educação da Bahia, a partir da necessidade de ofertar à Rede Estadual de Ensino, uma ferramenta específica para inserção dos planos de curso em uma plataforma virtual que utiliza uma base de dados integrada com o Sistema de Gestão Escolar - SGE - e Sec Online.

Diante dos estudos dos diversos modelos de implantação de Políticas Públicas (PP) analisados no componente - Políticas Públicas Comparadas - no Programa de PósGraduação em Estado e Sociedade (PPGES) pela Universidade Federal do Sul da Bahia (UFSB) e de parceria com o outro autor desta proposta deste ensaio, surgiram diversos questionamentos.

\footnotetext{
${ }^{1}$ Outrora denominado Colégio Estadual Pedro Álvares Cabral - CEPAC, o CIEPS é um dos colégios mais antigos de Porto Seguro. Em 2016, o Governo do Estado da Bahia formou uma parceria com a Universidade Federal do Sul da Bahia (UFSB) e passou a realizar uma série de reformas com o objetivo de transformar a antiga escola em um colégio de ensino de/em tempo integral, com foco em novas perspectivas de ensino diretamente vinculadas à universidade.
} 


\section{APORTES SOBRE O ESTUDO DE CASO REALIZADO}

Como mencionado, este ensaio analisará a proposta do SIAPP a partir das diversas formas de implementação de Políticas Públicas, priorizando a perspectiva tradicional denominada top-down ou desenho prospectivo, forma essa utilizada pelo Governo do Estado da Bahia.

Serão apresentadas propostas alternativas para a viabilização do SIAPP, através da abordagem bottom-up ou desenho retrospectivo e ainda realizar um esforço de sugestão para implementar o sistema através da perspectiva da "mirada ao revés".

É importante salientar que a análise será feita a partir dos "burocratas de nível de rua”, ou seja, dos professores da rede estadual de ensino, em particular, do Complexo Integrado de Educação de Porto Seguro - CIEPS -, que responderam a um questionário piloto a respeito da problemática.

Conforme a Superintendência de Políticas para a Educação Básica (SUPED), o SIAPP foi criado com a finalidade de fortalecer o planejamento do professor, produzir estudos e pesquisas, subsidiar o acompanhamento pedagógico, possibilitar o replanejamento de forma a garantir aprendizagens e para construir propostas pedagógicas para políticas educacionais.

A atuação ocorre nas seguintes dimensões, organizadas hierarquicamente (figura 1).

Considerando a hierarquia demonstrada, a Secretaria de Educação da Bahia (SEC) responde somente ao secretário de educação, Walter Pinheiro, e ao governador, Rui Costa (PT).

A SEC possui 27 Núcleos Territoriais de Educação (NTE) e os Núcleos representam a Secretaria na Administração Regional que recebem apoio da sede, bem como desenvolvem programas que fortalecem a ação da Secretaria junto aos municípios do Estado. Os Núcleos acompanham os Territórios de Identidade da Bahia³.

\footnotetext{
${ }^{2}$ O Complexo Integrado de Educação de Porto Seguro - CIEPS, que foi objeto de estudo neste trabalho está vinculado ao NTE 27, sediado em Eunápolis.

3 Decreto no 15.806 de 30 de dezembro de 2014 - Dispõe sobre a organização territorial dos Núcleos Territoriais de Educação, e dá outras providências.
} 
Figura 1: Hierarquia de implementação do programa SIAPP usado pelo governo do estado da Bahia.

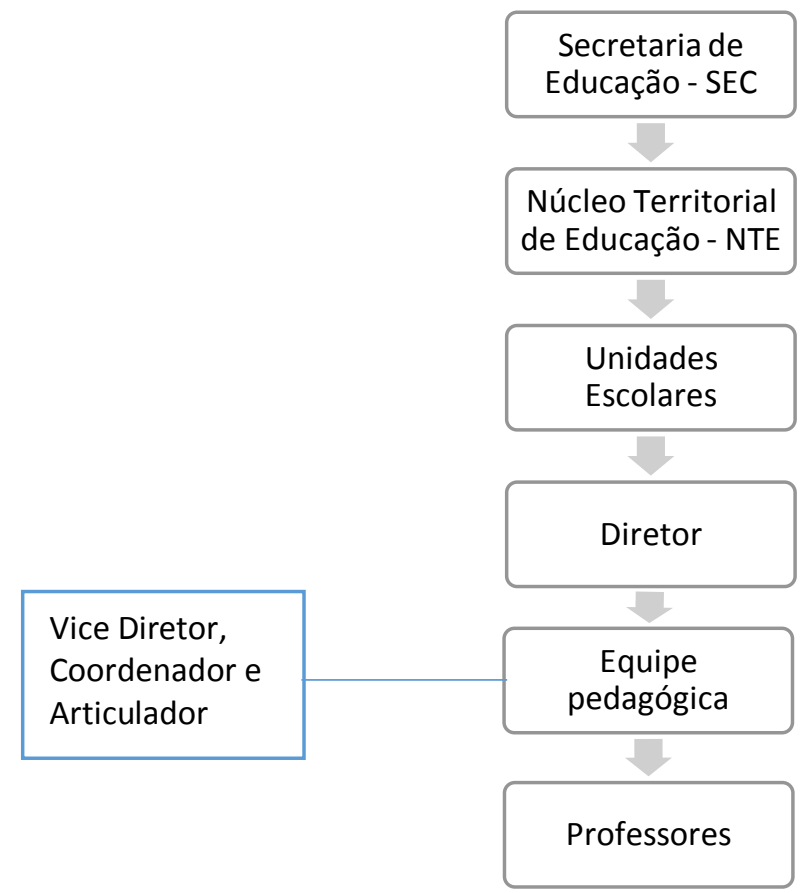

Fonte: MACHADO, 2018 - organização do autor.

Com o objetivo de identificar prioridades temáticas definidas a partir da realidade local, possibilitando o desenvolvimento equilibrado e sustentável entre as regiões, o Governo da Bahia passou a reconhecer a existência de 27 Territórios de Identidade, constituídos a partir da especificidade de cada região. Sua metodologia foi desenvolvida com base no sentimento de pertencimento, em que as comunidades, através de suas representações, foram convidadas a opinar.

Segundo a Coordenação de Fortalecimento à Gestão Pedagógica, vinculada à SEC, o docente utilizará o sistema para elaborar seus planos de curso e gerar banco de dados para os relatórios. Para tanto, realizará o próprio cadastramento.

Em relação ao Vice Diretor, Coordenador Pedagógico e Articulador de Área, poderão visualizar todos os planos de curso da unidade escolar, emitir todos os relatórios disponíveis e articular os planos de curso com as Diretrizes Nacionais da Educação Básica, com as Orientações Curriculares da SEC e, ainda, com o Projeto Político Pedagógico da escola.

Ao Diretor serão destinadas duas atribuições: a primeira, de dimensão administrativa, será a de cadastrar os vice-diretores, coordenador pedagógico e 
articuladores de área. A segunda, de dimensão pedagógica, a de acessar as mesmas possibilidades da equipe pedagógica.

Ainda conforme a SEC, as possiblidades pedagógicas para o SIAPP são subsidiar os estudos e análises pedagógicas durante as Atividades Complementares; analisar os planos de curso, por série e por turno na Unidade Escolar visando ao maior alinhamento; realizar proposições de replanejamento dos planos de curso, metodologias e demais atividades pedagógicas que melhorem as aprendizagens dos estudantes; acompanhar as postagens dos planos de curso no sistema e produzir relatórios de acompanhamento dos planos e de conteúdo.

Dessa forma, este ensaio foi produzido visando a compreender a problemática da implementação do SIAPP enquanto política pública, privilegiando a visão dos professores do Complexo Integrado de Educação de Porto Seguro - CIEPS.

\section{ALGUMAS DISCUSSÕES E FUNDAMENTAÇÕES TEÓRICAS}

Lima e D’Ascenzi (2013) no artigo “Implementação de Políticas Públicas: perspectivas analíticas" afirmam que existem duas abordagens preeminentes na literatura sobre implementação de políticas públicas. Uma delas tem por foco de análise o processo de formulação de política pública e as variáveis destacadas são referentes às normas que a estruturam. A outra abordagem enfatiza os elementos dos contextos no qual a política pública será implementada, tomando como variáveis as condições dos espaços locais e as burocracias implementadoras.

A primeira é denominada de "top-down", ou desenho prospectivo, (ELMORE, 1996 apud LIMA \& D’ASCENZI, 2013; HAM \& HILL, 1993). Fundamenta-se na abordagem sequencial, sendo a política pública vista como uma sequência de etapas distintas e guiadas por lógicas diferentes. A formulação seria permeada pela lógica da atividade política, sendo que a implementação estaria na competência da prática administrativa. "A implementação corresponderia à execução de atividades [...] com vistas à obtenção de metas definidas no processo de formulação das políticas" (SILVA \& MELO, 2000, p. 4 apud LIMA \& D’ASCENZI, 2013, p. 102). 
Uma vez criada a política, ocorreria um processo técnico de implementação, deixando evidente a distinção entre decisão e operacionalização.

A implementação de uma política pública é definida em termos de uma relação com a política e é errôneo aceitar como verdadeiro que esse processo é suave e direto (HAM \& HILL, 1993).

Em uma entrevista com uma representante do NTE 27, foi constatado que o SIAPP foi idealizado pelo atual secretário de educação do estado da Bahia, Walter Pinheiro, em 2016. 0 sistema então foi criado pelo Centro de Monitoramento On-line (CMO) e implantado a toda a rede de ensino estadual em 2017.

É importante ressaltar que, segundo a mesma representante, não houve qualquer tipo de Portaria ou Norma legal instituída pelo governo do estado para a criação do SIAPP, bem como a implantação de um projeto piloto, o que prejudica a fundamentação teórica, a segurança jurídica e o trabalho dos burocratas de nível de rua - que será abordado adiante.

Ainda conforme a representante do NTE 27, a proposta inicial do SIAPP é de formalizar o Plano de Curso de cada componente curricular de modo que as instâncias superiores (articuladores, coordenadores pedagógicos, vice-diretores, diretores, NTE e, claro, a SEC) tivessem acesso ao que está sendo pensando em relação à prática pedagógica. Contudo, o objetivo final seria substituir o SGE, principal sistema utilizado pelo SEC para o lançamento de notas e emissão de relatórios.

Considerando que a implementação da política pública é uma consequência, a explicação para a sua trajetória está no processo que lhe deu origem. Dessa forma, a análise é centrada nas normas que estruturam a política e suas lacunas (LIMA \& D’ASCENZI, 2013). Corrigir essas lacunas significa manter a política clara, evitar ambiguidades na formulação do objetivo, do financiamento e das responsabilidades e manter controle efetivo sobre os implementadores, limitando a margem de manobra dos implementadores (HILL, 2007 apud LIMA \& D’ASCENZI, 2013).

Ponderando uma complexa literatura para as políticas públicas Lima \& D’Ascenzi (2013) e Ham \& Hill (1993) sistematizam as referidas contribuições em quatro tipos de variáveis que influenciam o êxito do processo de implementação.

O primeiro refere-se à existência de tecnologia de intervenção disponível e acessível, de uma teoria causal válida e o tamanho da população-alvo. o segundo fundamenta-se no 
grau em que o plano estrutura a implementação, sendo que seu sucesso é decorrente da clareza dos objetivos, maior ou menor resistência ao plano, bem como a previsão e a disponibilidade de recursos, principalmente o financeiro. O terceiro alude ao contexto, ou seja, ao apoio público, às mudanças de governo e ao apoio das elites. O quarto visa à disponibilidade e qualidade dos recursos humanos e da estrutura organizacional. (LIMA \& D’ASCENZI, 2013; HAM \& HILL, 1993).

\section{UMA POSSIBILIDADE DE PROPOSTA}

O segundo modelo analítico que foi balizado neste ensaio é o "bottom-up", ou desenho retrospectivo. Esse modelo considera duas questões: (1) o da influência decisiva dos formuladores sobre o processo de implementação e (2) o de que as diretrizes explícitas, a determinação precisa de responsabilidades administrativas e a definição exata de resultados aumentam a probabilidade de êxito. O sucesso é condicional, sendo relacionado à capacidade limitada dos atores de cada nível de implementação de influenciar o comportamento daqueles dos outros níveis. (ELMORE, 1996 apud LIMA \& D’ASCENZI, 2013).

Neste modelo analítico, a burocracia responsável pela dinâmica de funcionamento é denominada de "street-level bureaucracy" ou burocracias de nível de rua.

Esta burocracia é definida como:

[...] as agências nas quais os trabalhadores interagem diretamente com cidadãos no curso de suas tarefas e que têm substancial discrição na execução de seu trabalho. As decisões tomadas pelos burocratas de nível de rua, as rotinas que estabelecem e os dispositivos que criam para lidar com as incertezas e pressões do trabalho efetivamente tornam-se as políticas públicas que implementam. O papel de policy making desses burocratas é construído sob duas facetas inter-relacionadas de suas posições: o alto grau de discrição e a relativa autonomia em relação à autoridade organizacional. [...] as condições de trabalho é que determinam esse tipo de burocracia (LIPSKY, 1980 apud LIMA \& D’ASCENZI, 2013, p. 104).

Estes trabalhadores se veem como dentes de engrenagens do sistema, sendo oprimidos pela burocracia dentro da qual trabalham. No entanto, eles parecem ter, muitas vezes, um grande grau de liberdade discricionária e autonomia. Isto é particularmente 
verdade para os professores e assistentes sociais que retêm um certo grau da autonomia permitida aos profissionais. (LIPSKY, 1980 apud HAM \& HILL, 1993).

[...] as pessoas, muitas vezes, ingressam num emprego público com, pelo menos, um compromisso com o serviço. Contudo, a própria natureza deste trabalho impede-os de chegarem perto da concepção ideal de seus empregos. Grandes quantidades de clientes ou cargas enormes de trabalho e recursos inadequados combinam-se com as incertezas dos métodos, e com a imprevisibilidade e o comportamento agressivo de clientes que ameaçam as aspirações que nutrem como funcionários públicos (LIPSKY, 1980 apud HAM \& HILL, 1993, p. 187).

Neste trabalho, os professores do CIEPS são os burocratas de nível de rua. Os responsáveis pela implementação das políticas públicas, em especial, a do objeto de estudo deste ensaio, o SIAPP, bem como de sua funcionalidade. Os autores supracitados destacam as características mais relevantes desta burocracia:

1. Os recursos são cronicamente inadequados para as tarefas a serem desenvolvidas;

2. A demanda pelo serviço tende a aumentar até encontrar a oferta;

3. Os objetivos dos serviços públicos tendem a ser vagos, conflitantes e ambíguos, sendo que não raras vezes representam horizontes desejáveis e não alvos fixos.

4. É difícil medir a performance desses trabalhadores, logo a definição de performance adequada é altamente politizada

5. A perda de clientes não é determinante do comportamento dos burocratas de nível de rua.

Desse modo, Lipsky (1980) ao ser citado por Lima \& D’Ascenzi (2013) afirma que os burocratas de rua, para lidar com as incertezas do trabalho, desenvolvem três respostas. (1) Organizam seu trabalho para obter soluções dentro dos constrangimentos que encontram. (2) Modificam o conceito de seu trabalho, restringem seus objetivos e reduzem o fosso entre recursos disponíveis e objetivos atingidos. (3) Transforma o conceito de cliente para tornar mais aceitável tal fosso entre realizações e objetivos.

Em síntese, é possível afirmar que os modelos apresentados, top-down e bottom-up, diferenciam-se quanto ao foco da análise. O primeiro, nas características da estrutura normativa; o segundo, nos atores implementadores e suas ações ao nível de rua. Em comum, 
enfatizam as condições e limitações materiais, vistas como determinantes da trajetória do processo de implementação. Essa ênfase permite a inserção de variáveis ligadas às ideias, aos valores e às concepções de mundo dos atores.

\title{
UMA ALTERNATIVA DE PROPOSTA OU PROPOSTA ALTERNATIVA
}

Uma proposta alternativa aos dois sistemas tradicionais supracitados é a mirada ao revés. Este modelo assume o problema ou bem público como unidade analítica central do processo de políticas públicas, insistindo na qualidade de público atribuído à política como reforçativo tradutor da policy, não mais ao ator que a ativou, mas, sim ao problema ou bem que a gerou (BOULLOSA, 2013).

Considerando a mirada ao revés, a política pública assume a definição de:

\begin{abstract}
“[...] um fluxo de ações e intenções ativadas por diferentes atores que buscam governar (inclusive definindo) problemas públicos ou bens públicos de acordo com suas compreensões de tais problemas ou bens, mas também de acordo com seus poderes de governabilidade, de mobilizar de recursos e de influenciar os demais atores (BOULLOSA, 2013, p. 77)
\end{abstract}

Nesta perspectiva desenvolvida, é o interesse público que justifica a ação social razoavelmente organizada, ocorrendo em duas dimensões: (1) compete ao governo de problemas que são considerados como de pública relevância para estes mesmos atores e (2) pertence à preservação e manutenção do conjunto de bens considerados como públicos por uma dada sociedade.

Para mirada ao revés, a política pública não é feita e sim conformada por diferentes materiais deixados ao longo de cursos de ação empreendidos pelo conjunto de atores mobilizados por aquele problema ou bem público, de modo que a dupla unidade fundamenta o seu olhar e a sua ação. A política pública é, então, “o conjunto de cursos de ação empreendidos pela multiatorialidade interessadas naquele problema" (BOULLOSA, 2013, p. 80). 
Ao assumir que a política pública é um construto, a principal tarefa do analista é a reconstrução daquele fluxo que ele identificou a partir do seu próprio olhar.

Assim, a gestão social para a mirada ao revés pode ser entendida como o conjunto de processos e dinâmicas que ativam e conformam o fazer juntos ou, ainda, a vontade de atores que agem no fluxo de políticas públicas tendo em comum o interesse em problemas de pública relevância (BOULLOSA, 2013).

\section{IMPLEMENTAÇÃO DO SIAPP NO COMPLEXO INTEGRADO DE EDUCAÇÃO DE PORTO SEGURO}

Em entrevista ${ }^{4}$, um gestor escolar afirma que o SIAPP é uma ferramenta boa, de fácil acesso e que agilizará o trabalho de professores e da gestão escolar, melhorando a qualidade no planejamento. Como afirma Barreto (2018), diferente do que advoga o gestor escolar, o SIAPP, é lento e não é inteligente nem amigável. Trava, não salva as informações e alterações no formulário de forma ágil. Para esta ação, todas as vezes que a informação é digitada e salva, o sistema reinicia da página principal, sendo que muitas das vezes se perde todo o conteúdo digitado.

Durante a implementação do SIAPP no Complexo Integrado de Educação de Porto Seguro, a partir da jornada pedagógica de 2017, foi realizada a Observação Participante, de modo que foi constatada muita resistência ao programa.

A conexão de internet na escola apresenta problemas frequentemente e o próprio sistema possui travamentos e inconstâncias operacionais de toda ordem, desde informações que não eram salvas, sendo necessário repetir todo o procedimento, dificuldade de acesso com invalidação de senha e, até mesmo, com informações obrigatórias do próprio sistema que "desaparecem", inviabilizando a execução, custando o já escasso tempo do professor. Por essas razões iniciais, o sistema já apresentava elevado índice de rejeição.

\footnotetext{
${ }^{4}$ Entrevista concedida ao site Ligação Direta Notícias, no dia 11 de outubro de 2017. Disponível em:

$<$ http://ldnoticias.com.br/noticias/35569,secret-rio-da-educa-o-dialoga-com-gestores-escolares.html $>$. Acesso em 15 ago. 2018.
} 
Diante de tal situação, foi realizado o Estudo de Caso em 2018, com aplicação de um questionário piloto aos professores do CIEPS, de modo a avaliar a forma de implementação feita pelo governo do Estado do programa SIAPP.

Neste sentido, a primeira pergunta foi: Qual a sua opinião sobre a pertinência do SIAPP? As respostas foram em forma de nota escalonar de 0 (zero), sem pertinência, à 5 (cinco) muito pertinente. A maior parte dos professores não consideraram o programa com pertinência significativa.

Na segunda pergunta foi indagada a opinião sobre a clareza dos objetivos do SIAPP. As respostas foram em forma de nota escalonar de 0 (zero), sem clareza, a 5 (cinco) muito claro. Nenhum professor considerou ter clareza total sobre o programa e a grande maioria não vê clareza significativa nos objetivos do SIAPP.

A terceira pergunta foi relacionada à existência de um tutorial ou treinamento prévio para a utilização do programa. As respostas foram limitadas a "sim" ou "não", mas o respondente poderia opinar, contudo, nenhum o fez. Além disso, a grande maioria dos entrevistados não teve nenhum tipo de tutorial ou treinamento para executar o programa.

Por fim, foi questionado de que forma o governo do Estado da Bahia deveria implementar o SIAPP.

Todos os entrevistados discordam da forma como o SIAPP está sendo implantado, de modo que uma pequena parcela $(9,1 \%)$ chega a acreditar que o sistema nem deveria ser ativado. Divididos em igual forma (45,5\%) uma parte dos demais respondentes acredita que deveriam ser realizados testes e outra parte que os professores precisariam ser consultados antes da implantação da política pública.

Talvez, a clara distinção entre decisão e operacionalização seja o único sucesso do modelo de implementação de política pública top-down em relação ao SIAPP, estando bastante evidente a decisão de criação do sistema pela SEC, na pessoa do Secretário de Educação e operacionalizada pelos professores das unidades escolares.

Em relação às demais características do modelo, várias são aplicadas de maneira equivocada, tendo por consequência o fracasso apresentado na pesquisa piloto. 
Quanto à análise ser centrada nas normas que estruturam a política e suas lacunas, a ausência de normas estabelecidas na criação da PP é um dos principais pontos do fracasso do sistema.

Além disso, a literatura propõe evitar ambiguidades na formulação do objetivo, sendo a clareza dos mesmos uma variável importante no processo de implementação. Tais ambiguidades, aparentemente, nasceram concomitantemente ao SIAPP, ao ser criado para construir plano de curso mas com objetivo final de substituir o SGE.

Outra variável importante é a qualidade dos recursos humanos e da estrutura organizacional, evitando ambiguidades das responsabilidades. Os professores ao tentarem recorrer aos seus superiores para a solução dos problemas encontrados, se deparam com o tradicional “jogo de empurra” sem determinar os devidos responsáveis pelo sistema.

A ausência de normatização quando da idealização e criação do SIAPP fazem com que os burocratas de nível de rua tenham uma tendência a rejeitarem o sistema, uma vez que existe uma tendência a mostrar uma afeição particular por regras que protegem o sistema interno de relações sociais, realçando o status dos mesmos, dado que as regras os habilitam a lutarem pelo respeito da organização e os protegem do conflito com clientes mediante a ênfase na impessoalidade. Devido à função em proporcionar segurança, regras deste tipo têm grandes chances de serem transformadas em ilimitadas. Neste sentido, metas políticas são distorcidas e meios são tratados como fins. (MERTON, 1957 apud HAM \& HILL, 1993, p. 182).

Se com as regras já há grande chance de serem transformadas em ilimitadas, a ausência delas, como a implementação do SIAPP, aponta para o fracasso quase que imediato do sistema.

\section{ALGUMAS TESSITURAS FINAIS}

Este ensaio apresentou duas propostas alternativas para a implementação do SIAPP, considerando que ele é importante e fundamental para a modernização do sistema de ensino. 
A primeira foi a bottom-up, ou seja, de baixo para cima. Esta proposta foca no trabalho realizado pelo burocrata de nível de rua, no caso do objeto deste estudo, o professor.

Uma de suas premissas fundamentais é a de que as diretrizes explícitas, a determinação precisa de responsabilidades administrativas e a definição exata de resultados aumentam, consideravelmente, a probabilidade de êxito.

Desse modo, se a SEC formular as normatizações necessárias, determinando as devidas responsabilidades a cada nível e definindo exatamente o resultado desejado, a chance de êxito aumenta consideravelmente.

Contudo, o sucesso é condicional, sendo relacionado à capacidade limitada dos atores de cada nível de implementação de influenciar o comportamento daqueles dos outros níveis. Além disso, as incertezas do trabalho fazem com que os burocratas de nível de rua organizem seu trabalho para obter soluções dentro dos constrangimentos que encontram e modificam o conceito de seu trabalho, restringindo seus objetivos.

A segunda proposta, considerada alternativa por não ser expressivamente presente na literatura, é a mirada ao revés. Nesta proposta, a política pública é um conjunto de ação feita pelos diversos atores interessados naquele problema e o foco não é mais o ator que a criou e, sim, o problema ou bem que a gerou.

A principal tarefa do analista é a reconstrução do fluxo que ele identificou a partir de seu próprio olhar.

Construir de forma moderna os Planos de Curso de cada componente curricular de uma unidade escolar é fundamental para o trabalho satisfatório ao longo do ano. Considerando essa proposta inicial do SIAPP, é essencial que o principal responsável pela sua reconstrução seja o professor, o principal ator/analista que deve lidar com o problema/bem, que é o SIAPP. Esse desejo ficou evidenciado na pesquisa piloto que foi realizada com os professores do CIEPS.

Por serem os implementadores das políticas públicas, os professores deviam ser ouvidos e, melhor, serem os analistas da política pública, propondo uma solução que de fato privilegiaria seu trabalho ao invés de se tornar um ônus. 


\section{REFERÊNCIAS}

BARRETO, R. S. Formação continuada para educadores: o curso Uso Pedagógico de Tecnologias Educacionais (UPTE) e Curso de Aperfeiçoamento em Tecnologias Educacionais (CATE 2). Virtual Educa. Salvador: 2018.

BOULLOSA, R. F. Mirando ao revés nas políticas públicas: notas sobre um percurso de pesquisa. Revista Pensamento e Realidade. Ano 16. V. 28. N. 3. 2013.

BAHIA. Decreto no 15.806 de 30 de dezembro de 2014 - Dispõe sobre a organização territorial dos Núcleos Territoriais de Educação, e dá outras providências.

HAM, C.; HILL, M. O processo de elaboração de políticas no Estado capitalista moderno. Campinas, tradução: Renato Amorim e Renato Dagnino, adaptação e revisão: Renato Dagnino. 2 ed. Londres: 1993.

LIMA, L. L.; D’ASCENCZI, L. Implementação de Políticas Públicas: perspectivas analíticas. Revista de Sociologia e Política. Curitiba. V. 21. N. 48 dez 2013.

\section{(cc) EY}

Este trabalho está licenciado com uma Licença Creative Commons - Atribuição 4.0 Internacional. 